Motrivivência $\quad$ v. $27, \quad$ n. $44, \quad$ p. $79-92$, maio/2015

http://dx.doi.org/10.5007/2175-8042.2015v27n44p79

\title{
A COPA DO MUNDO DE FUTEBOL EM BELO HORIZONTE-MG: impactos e legados
}

\author{
Carlos Eduardo Dias Munaier Lages \\ Silvio Ricardo da Silva ${ }^{2}$ \\ Luciano Pereira Silva ${ }^{3}$ \\ Fernando Mascarenhas ${ }^{4}$
}

\section{RESUMO}

Investigou-se os impactos e legados da Copa do Mundo anunciados para a cidade de Belo Horizonte. Metodologicamente, a pesquisa foi de caráter qualitativo. Como técnica de coleta de dados, foram entrevistados seis gestores. Concluiu-se que há subordinação da lógica do evento aos interesses econômicos de certos grupos, o que limita os ganhos sociais que se poderia obter. Os gestores enxergam a realização do megaevento como "negócio" e oportunidade de antecipar decisões e recursos governamentais, de aumentar o fluxo de turistas e de promover a imagem da cidade. Dessa forma, os principais legados consistiriam naqueles econômicos, de infraestrutura e de capacitação.

Palavras-chave: Copa do Mundo; Futebol; Legado

1 Mestre em Estudos do Lazer. Belo Horizonte / Minas Gerais, Brasil.

E-mail: cadu_lages@yahoo.com.br

2 Doutor em Educação Física. Docente da UFMG. Belo Horizonte / Minas Gerais, Brasil.

E-mail: prof.srs@gmail.com

3 Doutorado em Educação. Docente da UFMG. Belo Horizonte / Minas Gerais, Brasil.

E-mail: Ipereira45@hotmail.com

4 Pós-doutorado em Política Social. Docente da UnB. Brasília / Distrito Federal, Brasil.

E-mail: fernando.masca@uol.com.br 


\section{INTRODUÇÃO}

A realização da Copa do Mundo de Futebol no Brasil tem suscitado diversos debates acadêmicos. Entre estes, destacam-se análises sobre possíveis impactos que tal evento promoveu em nosso país.

Para que os jogos ocorressem no Brasil, foram feitas uma série de exigências da Federação Internacional de Futebol (FIFA). Para cumpri-las, cada cidade sede escolhida teve que passar por uma série de ajustes e reformas estruturais. Como conseqüência das mudanças e investimentos que ocorreram, a cidade de Belo Horizonte, como uma das sedes da Copa, sofreu impactos em diferentes áreas. $\mathrm{O}$ esporte e o lazer são algumas dessas áreas.

$\mathrm{O}$ alto grau de complexidade determinado pela FIFA exigiu um esforço e um modelo de organização integrado entre Federação, Estados e cidades-sede. Nessa direção, foi constituído, para Belo Horizonte, um Planejamento Estratégico Integrado (PEI) que contou com 54 projetos direcionados a diferentes áreas. O objetivo da criação deste foi criar ferramentas de gestão que pudessem garantir uma utilização eficaz dos recursos necessários para a implementação de projetos vinculados à realização da Copa. Nesse sentido, a Prefeitura e o Governo estabeleceram, conjuntamente, a visão que desejavam alcançar: "Minas Gerais e Belo Horizonte Integrados na gestão da Copa de 2014 como alavanca para o desenvolvimento econômico, social e cívico." (MINAS GERAIS; BELO HORIZONTE, 2009, p.11)

Tal compromisso foi instituído também, pelo Decreto Estadual n. 45.112 de 2 de junho de 2009 e posteriormente modificado pelo Decreto n. 45.345 de
19 de abril de 2010, o Núcleo de Gestão das Copas, presidido por Tadeu Barreto Guimarães, Coordenador Executivo do Programa Estado para Resultados (EpR), e composto pelos dirigentes das Secretarias de Estado de Esportes e Juventude (SEEJ), Planejamento e Gestão (SEPLAG), Desenvolvimento Econômico (SEDE), Turismo (SETUR), Transportes e Obras Públicas (SETOP), bem como do Banco de Desenvolvimento de Minas Gerais (BDMG). Através do mesmo decreto foi criado o Comitê Executivo das Copas dirigido pelo Coordenador Executivo do Programa Estado para Resultados. Estabeleceu-se ainda que a coordenação das ações referentes à Copa de 2014 que abarcavam as áreas de infraestrutura esportiva, de transporte terrestre e aéreo, turística, de saúde e segurança pública, comunicação, dentre outras estaria a cargo dos membros do Escritório de Gerenciamento de Projetos das Copas, órgão vinculado ao EpR.

A execução do Planejamento Estratégico Integrado (PEI) passou a ser, mediante o contexto apresentado, peça central nas possíveis melhorias sociais que ocorreram e ainda podem ocorrer na cidade com a realização da Copa. Para que isto de fato se efetivasse, os gestores responsáveis pela execução do PEI foram atores fundamentais neste processo.

Nesta perspectiva, este estudo teve como objetivo investigar, a partir da voz dos gestores, quais impactos e legados da Copa do Mundo foram anunciados para a cidade de Belo Horizonte destacando possíveis alterações nas vivências de esporte e lazer do belorizontino.

A partir da escolha do Brasil para sediar megaeventos esportivos, diversos estudos têm sido publicados no periodismo científico inerente ao campo da Educação 
Física e outras áreas relacionadas. Podemos citar, como exemplos, os trabalhos de Gastaldo (2009), Damo (2012) e Mascarenhas (2012), o primeiro publicado na Revista Brasileira de Ciências do Esporte e os dois últimos na Revista Movimento. Há também periódicos que organizaram dossiês relacionados a tal temática, como o denominado "Manifestações populares, cidadania e megaeventos esportivos", publicado em 2013 pela Revista Motrivivência. As publicações citadas, entre outras, debatem a ocorrência dos megaeventos no Brasil, mas nenhum trabalho dialoga diretamente com a concepção dos gestores. Assim, este estudo optou por destacar os olhares dos gestores devido aos poucos estudos existentes que privilegiam tais sujeitos como foco de investigação. Além disso, através da análise de suas ideias como ponto de partida, é possível delinear de forma mais assertiva hipóteses, interesses, atores envolvidos e estratégias de ação, entendendo os fundamentos pelos quais são tomadas as decisões e são construídas as políticas públicas de esporte e lazer (MENICUCCI, 2008).

Para cumprir os objetivos pretendidos nessa investigação adotou-se como opção metodológica a pesquisa de campo, de caráter qualitativo. Como técnica de coleta de dados, foram entrevistados seis gestores $^{5}$ durante a preparação da cidade para receber a Copa do Mundo de Futebol, assim distribuídos: dois responsáveis gerais por todos os projetos do Planejamento Estratégico Integrado (PEI) de Belo Horizonte, um pertencente à esfera estadual e outro integrante da esfera municipal, e quatro gestores relacionados com os seguintes projetos: Modernização do Mineirão, Estádios Alternativos e Mobilidade Urbana. A análise das entrevistas foi feita à luz da técnica da análise de conteúdo, apresentada por Bardin (1979). A análise de conteúdo, de acordo com os apontamentos do autor, versa sobre a descoberta de significações de diversos tipos de discursos, baseando-se na inferência ou dedução, mas que concomitantemente respeitem a critérios específicos propiciadores de dados em freqüência em estruturas temáticas, buscando exprimir e revelar a riqueza de detalhes.

O quadro a seguir informa algumas características dos entrevistados: 
Quadro 1: Perfil dos entrevistados

\begin{tabular}{|c|c|c|c|c|c|}
\hline Entrevistado & Formação & Experiência Profissional & $\begin{array}{l}\text { Experiência } \\
\text { na área de } \\
\text { esporte e } \\
\text { lazer }\end{array}$ & $\begin{array}{c}\text { Função/ } \\
\text { Cargo }\end{array}$ & $\begin{array}{l}\text { Projetos do } \\
\text { PEI que atua }\end{array}$ \\
\hline A & $\begin{array}{l}\text { Graduação } \\
\text { em Admi- } \\
\text { nistração } \\
\text { Pública e } \\
\text { em Ciências } \\
\text { Econômicas. }\end{array}$ & $\begin{array}{l}\text { Subsecretaria de Plane- } \\
\text { jamento e Orçamento } \\
\text { Programa Estado pra } \\
\text { Resultados Agenda de } \\
\text { Melhorias }\end{array}$ & Não & $\begin{array}{l}\text { Gerente do } \\
\text { programa } \\
\text { Copa 2014/ } \\
\text { Chefe de } \\
\text { gabinete da } \\
\text { Secretaria } \\
\text { Extraordiná- } \\
\text { ria da Copa }\end{array}$ & $\begin{array}{l}\text { Mineirão } \\
\text { e Estádios } \\
\text { Alternativos }\end{array}$ \\
\hline B & $\begin{array}{l}\text { Graduação } \\
\text { em Enge- } \\
\text { nharia Civil. }\end{array}$ & $\begin{array}{l}\text { Concessionária Rio-Juiz } \\
\text { de Fora, da Concer. }\end{array}$ & Não & $\begin{array}{l}\text { Diretor- } \\
\text {-presidente } \\
\text { da Minas } \\
\text { Arena }\end{array}$ & Mineirão \\
\hline $\mathrm{C}$ & $\begin{array}{l}\text { Graduação } \\
\text { em Enge- } \\
\text { nharia Civil. }\end{array}$ & $\begin{array}{c}\text { Secretaria do Transporte } \\
\text { de Minas Sindicato do } \\
\text { Transporte de Passagei- } \\
\text { ros BHTrans }\end{array}$ & Não & $\begin{array}{c}\text { Coorde- } \\
\text { nador do } \\
\text { Planeja- } \\
\text { mento da } \\
\text { Operação } \\
\text { da Mobi- } \\
\text { lidade pra } \\
\text { Copa. }\end{array}$ & $\begin{array}{l}\text { Mobilidade } \\
\text { Urbana }\end{array}$ \\
\hline $\mathrm{D}$ & $\begin{array}{l}\text { Graduação } \\
\text { em Admi- } \\
\text { nistração. } \\
\text { Especiali- } \\
\text { zação em } \\
\text { Finanças }\end{array}$ & $\begin{array}{l}\text { Samir Samarco Vale do } \\
\text { Rio Doce }\end{array}$ & Não & $\begin{array}{c}\text { Gerente } \\
\text { do Projeto } \\
\text { Sustentador } \\
\text { da Copa }\end{array}$ & $\begin{array}{l}\text { Todos esco- } \\
\text { lhidos para } \\
\text { análise }\end{array}$ \\
\hline E & $\begin{array}{c}\text { Especializa- } \\
\text { ção em Ad- } \\
\text { ministração } \\
\text { de Empresas } \\
\text { e em Geren- } \\
\text { ciamento } \\
\text { Executivo. } \\
\text { Mestrado } \\
\text { em Econo- } \\
\text { mia Interna- } \\
\text { cional. }\end{array}$ & $\begin{array}{c}\text { Cargil Ligth Bunge } \\
\text { Cemig Codemig BDMG }\end{array}$ & Não & $\begin{array}{l}\text { Secretário } \\
\text { Extraordiná- } \\
\text { rio da Copa }\end{array}$ & $\begin{array}{l}\text { Todos esco- } \\
\text { Ihidos para } \\
\text { análise }\end{array}$ \\
\hline $\mathrm{F}$ & $\begin{array}{l}\text { Graduação } \\
\text { em Enge- } \\
\text { nharia Civil. }\end{array}$ & BHTrans & Não & $\begin{array}{l}\text { Gerente } \\
\text { de Coorde- } \\
\text { nação de } \\
\text { Mobilidade } \\
\text { Urbana }\end{array}$ & $\begin{array}{l}\text { Mobilidade } \\
\text { Urbana }\end{array}$ \\
\hline
\end{tabular}




\section{A voz dos gestores}

Para atingir os objetivos propostos, passamos a apresentar e discutir relatos colhidos em entrevistas realizadas com seis gestores envolvidos no processo de formulação e/ou execução de projetos do Plano Estratégico Integrado - PEI.

Neste trabalho, destacamos duas categorias construídas a partir da análise dos relatos: ações propostas nos projetos investigados que podem incidir nas vivências de esporte e lazer dos belohorizontinos; e impactos e legados da Copa do Mundo de 2014 em Belo Horizonte.

Um primeiro olhar para os gestores entrevistados permite-nos afirmar que estes possuem uma heterogeneidade em suas formações educacionais e experiências profissionais. Porém, o que chamou a atenção foi o fato de que além dos entrevistados não fazerem parte das secretarias de educação, cultura, esporte ou políticas sociais, onde talvez se encontre um número maior de funcionários e gestores com experiência profissional no campo de esporte e lazer, nenhum destes possui experiência prévia na área. Esta condição não os desqualificam necessariamente para o gerenciamento dos projetos, até porque os 54 projetos integrantes do PEI abarcam diferentes áreas, mas ao se tratar da organização de um megaevento esportivo que abrange também elementos como cultura, esporte e lazer seria interessante a presença de um gestor que pudesse representar e trazer contribuições da área, bem como expor deficiências e demandas que poderiam ser levadas em consideração em todo o processo.

\section{Vivências de esporte e lazer}

Em relação às ações propostas nos projetos investigados que incidirão nas vivências de esporte e lazer dos belohorizontinos, podemos destacar algumas questões interessantes apontadas pelos gestores entrevistados que, na visão deles, podem alterar/influenciar na fruição do esporte e do lazer em Belo Horizonte. Uma ação citada pelos entrevistados, neste sentido, foi a construção da área externa do Mineirão, a "Esplanada".

[...] na parte externa do Mineirão, está se construindo uma grande esplanada, que é uma grande laje, em torno de 80 mil metros quadrados, que vai abraçar todo o estádio, ou seja, debaixo dessa laje você vai ter estacionamento, vai ter lojas, vai ter acesso ao estádio, enfim. E, por cima dessa laje, o público vai poder acessar, em dias de jogos, o estádio também. Então, vai ficar uma estrutura que deixa um pouco de ser um estádio e passa a ser um complexo multiuso (Entrevistado B).

O Mineirão vai ser o novo ponto focal da cidade em termos de o chamado grande parque, que vai ter todas as áreas de passeio, vai ter as lojas, vai ter várias lojas no Mineirão, lojas importantes, Museu do Futebol, visitação, a parte externa do Mineirão vai estar aberta diariamente pra população usar. Então vai ser, vamos dizer, o novo chamado Eldorado de visita (Entrevistado E).

Ao pensarmos nessa nova área criada e as possíveis relações que poderão ser estabelecidas com os belorizontinos, podemos destacar proposições de Raeder (2010). O autor adverte que, ao se construir e/ou remodelar equipamentos esportivos, é essencial que seja formulado paralelamente um plano de ocupação, bem como seja 
observado a sua distribuição e acesso para que possa realmente se converter em benefícios para a sociedade. Além disso, sobre o espaço reformado (esplanada do Mineirão), é importante salientar que ele já existia, tendo sido, ao longo da história, palco para diversas manifestações e eventos, como: feira de carros, shows musicais, passeios de bicicletas, prática de aeromodelismo, entre outros. Desta forma, não se trata do oferecimento de um espaço novo, mas de um remodelamento de uma estrutura já existente.

É comum a utilização pelos entrevistados do termo "modernização", ao referirem-se às reformas dos estádios. Tal termo, tanto para referir-se ao projeto "Modernização do Mineirão", quanto para o estádio Independência integrante do projeto "Estádios Alternativos", aparece relacionado a duas conotações diferentes. Inicialmente o termo aparece atrelado à expressão arena de multiuso, à ideia de superação dos equipamentos obsoletos e à substituição do torcedor pelo cliente.

No Independência, nós estamos falando... Em ambos os casos, modernização é criar um patamar novo de arenas multiuso. Ou seja, nós estamos acostumados em $\mathrm{BH}$ a não ter esse tipo de equipamento. Nossos equipamentos são absolutamente obsoletos do ponto de vista de conforto, segurança, nível dos serviços prestados (Entrevistado A).

Então, a questão que é uma exigência da FIFA para o Mineirão e que foi rebatida em alguma medida para o Independência, nesse projeto de modernização, é criar um novo conceito de arena multiuso que vai trazer com isso um novo conceito do negócio futebol, na medida em que você vai ter maior nível de conforto paro o cliente, para o torcedor, que deixa de ser um mero torcedor e passa a ser um cliente. Porque ele vai ter todo um serviço de camarote, de cadeiras, de bares com exclusividade. Fora que vai ser um equipamento que não vai ser só para práticas esportivas, é para shows, pequenos eventos, grandes eventos. (Entrevistado A)

Nesse ponto, vale ressaltar que, a partir dos depoimentos apresentados, pode-se perceber que cada vez mais as relações entre os equipamentos, as empresas, o Estado e população são afetadas por lógicas empresariais. Linhales (2001) argumenta que essa tentativa de modernização tem se configurado na adaptação e/ou submissão às dinâmicas e às demandas mercadológicas. Dessa forma, os espaços públicos se transformam em espaços privatizados e o lazer passa a ser considerado como atividade de entretenimento disponível para consumo, reforçando-se as injustiças sociais.

O vocábulo modernização também aparece, na fala dos gestores, relacionado à ideia de internacionalização, tecnologia e sustentabilidade. Nesse sentido, o novo Mineirão passa a ser visto como um modelo a ser seguido, um estádio que reflete o ideal de uma cidade que se atualiza de forma responsável, que se desenvolve economicamente sem deixar de lado a responsabilidade ambiental.

Aí, você vê a questão dos estádios de futebol. Nós estamos construindo o Mineirão, reformando o Mineirão. Vai ser um estádio pra 64.500 pessoas, um estádio super moderno, de um gabarito internacional em todas as suas instâncias, desde o apito e o gramado, até as arquibancadas. Aí, nós vamos ter o Mineirão totalmente sustentável. Vamos ter o Mineirão que vai ter as, vamos dizer, as placas fotovoltaicas para produzir energia solar para o Mineirão. Não vai ser uma energia que vai atender a toda demanda do Mineirão, mas vai ser uma energia que vai atender a 
uma grande parte do Mineirão. Aí, nós temos a recuperação das águas pluviais; aí, nós vamos ter uma recuperação do lixo. (Entrevistado E)

Um novo estádio, reflexo de uma cidade moderna, carece de cidadãos que coadunem com esta nova lógica. Assim, processos educativos podem direcionar o comportamento da população para o que se espera dela.

Essa questão de uma cidade e a gente hoje percebe, é uma cidade que gasta muito pra manter toda a sua estrutura urbana, os equipamentos urbanos e tal. E há um vandalismo tremendo! Pichação em tudo quanto é prédio, faixa de pano pra tudo quanto é lado, arrebenta banco de praça, destrói equipamento, telefone público, e por aí vai. Eu acho que isso é importante, que a Prefeitura faça um pouco um trabalho disso, investir na mudança de atitude. (Entrevistado C)

Na fala do gestor, fica evidente a visão da Copa como uma grande catalizadora de transformações sociais. Entretanto, há muita pouca clareza sobre como as mudanças poderão efetivamente ocorrer. Assim, o gestor sinaliza muito mais intenções genéricas sobre melhorias que a cidade precisa receber do que estratégias claras para que a cidade se beneficie por sediar o evento.

Em relação a outras ações que podem impactar nas vivências de esporte e lazer dos belohorizontinos, podemos destacar o anúncio de vários atos que têm como foco o torcedor, a partir de três linhas de concepção/atuação. A primeira segue a asserção de que o Mineirão, antes da reforma, não tinha ou tinha em condições deficientes, segurança, conforto e serviços de qualidade e que o novo estádio proverá um nível bem maior desses três elementos. Esse discurso faz referência à questão de modernização dos equipamentos, podendo-se perceber, nos relatos abaixo, elementos da teorização de Linhales (2001) que afirma que o processo de modernização anunciado pelos gestores tem se constituído, cada vez mais, na adequação e/ou subordinação às lógicas mercadológicas. Deve-se chamar a atenção também para um possível processo de elitização dos freqüentadores, bem como da restrição do acesso aos mesmos, devido a barreiras econômicas que podem ser intensificadas.

De novo, eu acho que é mudar um paradigma de torcedor. Quando o Mineirão estava aberto, é unânime a pergunta de: "quem já foi ao Mineirão?" - todos levantam a mão. "Quem gostou do serviço que teve no Mineirão?" - todos abaixam a mão. Ou seja, os serviços prestados nesses equipamentos eram muito aquém da demanda (Entrevistado A).

E você pode mudar esse conceito, ou seja, a idéia de camarote ela cresce. E quando você olha a experiência no mundo, seja Europa, seja Estados Unidos -, você vê que isso é um paradigma que funciona muito bem lá fora. E cada vez mais nosso nível de renda vai chegar a um patamar em que a gente tem uma nova oportunidade de um novo negócio, em que você não vai não só pra ver o jogo. Você vai almoça, fica lá, usa aquele espaço, acontece o jogo e você tem um momento de lazer ali, com jogo ou sem jogo (Entrevistado A).

A segunda linha abrange questões relacionadas ao comportamento do torcedor. Estas visam modificar/adequar tais comportamentos ao novo espaço e às demandas/ modelo da FIFA. Através dos relatos abaixo se pode notar que a concepção do gestor $B$ de estádio e torcedor parte da comparação com modelos norte-americanos e europeus. 
Assim, o gestor não considera a tradição do torcer existente antes da reforma do Mineirão. As modificações salvaguardadas pelo padrão FIFA caracterizam-se por um tom de imposição ao comportamento do torcedor.

A ideia nossa no Mineirão, e o projeto está sendo desenvolvido dessa forma, a visibilidade é $100 \%$ em todos os lugares do estádio. Você sentado vai ter perfeitamente condições de ver o jogo! Logicamente, tem aquele lance mais agudo, a torcida fica em pé, depois aquele chute passa raspando, não é, senta depois. (Entrevistado B)

O público não vai mudar. Mas o público vai ter que entender, você entende, também que não dá pra comer alguma coisa e jogar o papel no chão, não é?! O público que vai a jogo de futebol o que ele mais quer mesmo é ser bem tratado por aqueles que administram o estádio e, principalmente, torcer apaixonadamente pelo futebol. (Entrevistado E)

A terceira linha diz respeito à concepção que se tem da atuação e comportamento das torcidas organizadas e a promoção de "uma ética do torcer". Nesse sentido, o torcedor é abordado como cliente e seu comportamento como prejudicial ou benéfico para o "negócio".

Eu acho que nós temos uma questão de cultura. Ou seja, a questão de torcida organizada é uma questão um tanto quanto polêmica. Eu acho que eles têm o direito de se organizar enquanto torcedores, mas não de virar um grupo sem lei, que fica ativando violência e coisas do tipo, porque, de novo espanta o negócio. A questão de depredar um ativo não é, de novo, tolerável. $\mathrm{E}$ isso vai ter que ser obviamente aculturado, criar-se a cultura de valorização daquele ativo. Então, você vai ter uma segurança patrimonial muito maior do que você já tinha antes (Entrevistado A).
Campanhas de conscientização, no apoio dos clubes, não é, também, mostrando o que é o conceito do torcedor legal, o torcedor que veio realmente pra torcer, o torcedor que gosta do futebol. Acho que a gente tem que mexer muito é nessa questão do emocional das pessoas (Entrevistado B).

As afirmações dos gestores relacionadas ao torcer revelam um conhecimento sobre o assunto baseado no senso comum além de reforçar a visão mercadológica do futebol. Em sua nova conformação, o estádio, como arena esportiva, prevê o oferecimento de um "produto" mais sofisticado ao frequentador que, com isso, passa ter um novo valor de mercado. Consequentemente, tal produto passa a ser acessível a um número menor de pessoas.

Parece-nos sem fundamento a afirmação de que "o público não vai mudar" (Entrevistado E). Nesta nova lógica organizacional do futebol profissional, faz mais sentido presumir que estamos passando por um momento de transição em relação ao público que vai aos estádios (arenas), e que novas formas de se comportar nos eventos esportivos estão sendo gestadas. Neste processo, já claramente percebido no Mineirão, sai o torcedor organizado, e entra em cena o sócio-torcedor.

\section{Impactos e Legados}

As falas dos gestores sobre impactos e legados da Copa do Mundo foram produzidas principalmente a partir do seguinte questionamento: A atual gestão do(a) Estado de Minas Gerais/Prefeitura de Belo Horizonte têm qual objetivo para a cidade de Belo Horizonte através da organização e realização da Copa do Mundo de 2014? 
Chama atenção o fato de que os gestores vêem a realização da Copa do Mundo como um negócio e uma oportunidade de promover a imagem da cidade, como se pode perceber através dos relatos transcritos a seguir:

E, no fundo, o que a gente está buscando como grande impacto dessa Copa do Mundo é a questão de visibilidade, ou seja, da imagem do estado e da geração de novos negócios, ou seja, alavancar a economia, e esse impacto então até em termos de PIB com a Copa do Mundo (Entrevistado A).

Você tem uma atenção do mundo, que está toda voltada pra cá, não é? Os negócios são extremamente incrementados com a Copa do Mundo, a parte, a vida econômica de uma cidade, de um estado, de um país. A questão do esporte também ela fica bastante em evidência. Então, eu acho que tem um ganho técnico-esportivo também com a Copa do Mundo, ela deixa um legado (Entrevistado B).

Você está pensando num equipamento de 64 mil pessoas, como ele vai ser, 64 mil pessoas é o que vem de turista de negócio ao longo de talvez um ano, na cidade de Belo Horizonte. Você pode então, na medida em que você tem um grande evento, um grande clássico, um grande show, se você encher esse Mineirão de gente de fora, você tem, num dia, aquela movimentação de turistas e de serviço. E, aí, de novo, o impacto econômico é fundamental. Copa é negócio, Mineirão é negócio, futebol é negócio. É paixão, sem dúvida, mas é fortemente um espaço de negócio (Entrevistado A).

Friedmann (2005) defende o argumento de que o marketing urbano pode se configurar em um instrumento útil para o desenvolvimento das cidades, pois um posicionamento de marketing adequado e uma imagem positiva gerada agem como elementos facilitadores na atração de investimentos e no desenvolvimento econômico, cultural e social da cidade. O marketing urbano, de acordo com o autor, é importante para implementação de melhorias de uma determinada região, tendo com principais metas, tornar a cidade mais atraente e aquilatar um determinado local.

Porém, uma crítica à Friedmann é que este incorpora intrinsecamente ao processo uma concepção mercadológica à cidade, condicionando seu desenvolvimento ao atendimento das demandas do mercado. Isto fica claro na medida em que o autor trata os próprios cidadãos como clientes em suas conceituações.

Souza (2006) apresenta um contraponto afirmando que o marketing urbano pode contribuir positivamente para a cidade, desde que não seja utilizado para o mascaramento das demais problemáticas e vulnerabilidades presentes na urbe. $\mathrm{O}$ perigo, portanto, reside no aprisionamento a essa lógica de oferta e demanda do mercado.

Foi indagado aos gestores acerca das contribuições positivas e negativas que a realização da Copa do Mundo de 2014 poderá trazer para Belo Horizonte. Em relação às positivas foram recorrentes alguns elementos, em consonância com Villano e Terra (2008), que declaram que os principais impactos gerados na cidade sede são de natureza econômica, social, de infraestrutura e de reestruturação da imagem da mesma. O crescimento do turismo e a reconhecimento da imagem da cidade-sede, por exemplo, foram impactos citados pelos gestores, uma vez que acreditavam que ocorreria uma reestruturação da hotelaria e um fluxo maior de turistas, bem como a valorização da cidade e do país. 
Muito fluxo de turista, de negócios, de oportunidades de serviço é gigantesca. Fora isso, ficam todas as melhorias que não seriam possíveis sem a Copa do Mundo (Entrevistado A).

Sem dizer das melhorias que a gente consegue enxergar, que são mais palpáveis, que é a reforma, embelezamento da cidade, melhoria, aí, de asfalto, edifícios revigorados, recuperados. Enfim, é um evento muito interessante do ponto de vista de mostrar a cidade pro mundo. Foi o que eu falei, é o portal de passagem de uma cidade provinciana, pra uma cidade cosmopolita e tudo mais! A gente aprender a conviver com muitos povos na rua, no dia-a-dia, rede hoteleira e por aí vai (Entrevistado C).

Esses pensamentos vão ao encontro da pesquisa realizada pela New Zealand Tourism Research Institute, citada por Tavares (2011), que assevera que os megaeventos são ocasiões privilegiadas para a promoção de ações voltadas para o turismo das cidades e regiões. Estão também em conformidade com Villano et al. (2008) que afirmam que o país e as cidades sede terão uma projeção ampliada nacionalmente e internacionalmente, denominado por eles de legados de imagem. Na fala dos entrevistados, porém, não fica explícito um conhecimento técnico sobre o assunto, que contribua para uma melhor argumentação dos impactos positivos sobre a realização do evento. Assim, não se pode ter segurança sobre a existência de um planejamento consistente e responsável em relação aos investimentos que Belo Horizonte recebeu, o que prejudica, segundo Villano et al. (2008), a ocorrência dos legados.

Melhorias de infraestrutura e capacitação de mão de obra também foram citadas como possíveis contribuições positivas.
Eu acho que, com certeza, a gente vai ter um ganho em profissionalizar essa mão de obra nessa área, talvez em melhor condição tanto profissional, quanto até de idiomas, isso depende, na realidade do investimento da população em si, do interesse da população (Entrevistado D).

O legado que isso pode trazer? Os investimentos. [...] Se você pegar em segurança pública, se você pegar saúde, recentemente foi inaugurado um heliponto lá no hospital, no pronto-socorro do João XXIII, aqui no Centro. Corpo de Bombeiros está se aparelhando com mais equipamentos e tal pra combater incêndio e catástrofe e não sei mais o quê. Polícia Militar também, treinamento. O nosso próprio Plano de Operação de Transporte e Trânsito. Olha um plano desse tamanho, dessa abrangência que a cidade ganha, pra poder enfrentar questões de contingência, que possam acontecer na cidade. Então, nós estaremos muito mais preparados para prestar um serviço melhor para o cidadão (Entrevistado $\mathrm{C}$ ).

Podemos relacionar os relatos anteriores aos possíveis legados definidos por Villano et al. (2008) como legados em si e legados de conhecimento. Os primeiros consistiriam nas intervenções e obras realizadas nos equipamentos esportivos, de segurança e tecnologia, bem como na criação de empregos temporários, enquanto os últimos dizem respeito à transferência de conhecimento capaz de formar novos profissionais capacitados, gerar informações e incentivar a pesquisa e o desenvolvimento.

Foram citadas ainda como contribuições positivas a sustentabilidade, políticas tarifárias e o transporte para o lazer como iniciativas governamentais que podem refletir na mudança do comportamento das pessoas.

Já no que diz respeito às contribuições negativas que a realização da Copa 
do Mundo pode trazer para Belo Horizonte foram relatadas poucas questões por parte dos gestores. O entrevistado A levantou a possibilidade de ocorrer algum fato que gere uma imagem negativa para a cidade.

Se a gente fizer um trabalho mal feito, a imagem que é boa ela pode ser ruim. [...] Então, do mesmo jeito que a imagem pode ser uma imagem muito positiva, tanto por incapacidade nossa, quanto por tragédias, podem trazer imagens muito ruins para o mundo, do ponto de vista de um grande evento. Ou seja, você tem muita gente reunida, digamos que você tenha um atentado terrorista. Isso pode marcar como um grande legado negativo pra cidade (Entrevistado A).

O entrevistado B advertiu sobre a questão da sustentabilidade econômica pós Copa do Mundo, demonstrando preocupação com a manutenção dos serviços e do comércio da cidade caso não se tenha feito um bom planejamento capaz de assegurar a continuidade do fluxo de visitantes pós-megaevento.

O que pode ter de negativo, talvez vá ser, o que pode ser melhor ou pior nesse negativo a partir de um bom planejamento. É pensar no que fazer com o legado. E, depois da Copa, o quê que virá? O que acontece? Não vamos ter mais tanta gente na cidade, não vamos ter os turistas da Copa. Mas nós podemos ter outros turistas aqui que vão manter o nível de atividade que estava na época da Copa. É esse o planejamento que tem que se pensar, porque senão você vai ter desemprego em massa. Por exemplo: acabou a Copa, cadê os ocupantes do hotel? Não tem. Cadê os ocupantes aqui de um monte de táxi? Não tem. Então, você começa a ter um prejuízo de algumas classes, começa a ter desemprego, reduz o nível de atividade, em alguns setores, o setor do comércio, principalmente vai sentir muito (Entrevistado B).

\section{CONSIDERAÇÕES FINAIS}

Desde o anúncio da escolha do Brasil como sede da Copa do Mundo de Futebol muito se discutiu sobre os impactos e legados da realização deste evento em solo brasileiro. Passado o evento, resta a análise das mudanças que o evento de fato promoveu. Para esta tarefa, é importante destacar a visão dos gestores que estiveram à frente do planejamento e execução das ações preparativas da Copa, evidenciando o que foi anunciado.

Os megaeventos esportivos têm ganhado cada vez mais importância devido à sua grande audiência em nível mundial, à aliança formada entre esportes-mídia-negócios e à percepção por parte dos gestores e governantes do evento como uma grande oportunidade de promoção e desenvolvimento da cidade e/ou do país.

Como era de se esperar, marcou a fala dos gestores a subordinação de toda a lógica do evento à predominância de interesses de certos grupos econômicos, o que limita os ganhos sociais que se pode obter. Os gestores enxergam a realização do megaevento como um "negócio" e uma oportunidade de antecipar decisões e recursos governamentais, de aumentar o fluxo de turistas e de promover a imagem da cidade. Dessa forma, os principais legados consistiriam naqueles econômicos, de infraestrutura e de capacitação dos cidadãos que trabalharam no megaevento. Além disso, inclusive em virtude do perfil dos gestores (ausência de experiência na área esportiva), ficou pouco claro a expectativa 
dos mesmos em relação aos impactos da Copa do Mundo de Futebol nas vivências de esporte e lazer da população de Belo Horizonte. Exceção feita ao frequentador do novo Mineirão, torcedor que deve adaptar seu comportamento às novas diretrizes que o espaço apregoa.

O nível de legitimidade de uma política pública passa pelo grau de envolvimento da população com a mesma. No caso da Copa do Mundo de Futebol (e dos Jogos Olímpicos do Rio, outro megaevento), este envolvimento foi frágil, pois sediar um megaevento não foi uma demanda da população brasileira (MASCARENHAS, 2012). Mesmo assim, mediante os altos investimentos públicos realizados, os impactos e legados dos megaeventos devem ser objeto de reflexão de todos.

\section{REFERÊNCIAS}

BARDIN, Laurence. Análise de conteúdo. Lisboa: Edições 70, 1979.

DAMO, Arlei Sander. O desejo, o direito e o dever: a trama que trouxe a Copa ao Brasil. Movimento, Porto Alegre, v. 18, n. 2, p. 41-81, 2012.

FILGUEIRA, Julio Cesar Monzú. Importância dos legados de megaeventos esportivos para a política nacional do esporte: cidade, cidadania e direitos dos cidadãos. In: DACOSTA, Lamartine et al. (Editores). Legados de megaeventos esportivos. Brasília: Ministério do Esporte, 2008. p. 65-74.

FRIEDMANN, Reinhard. Marketing estratégico de cidades. Abaco. n.4445, Gíjon, 2005.

GASTALDO, Édison. Ritos da nação: uma videoetnografia da recepção coletiva da
Copa do Mundo no Brasil. Rev. Bras. Cienc. Esporte, Campinas, v. 31, n. 1, p. 209-222, set. 2009.

GOLDEN GOAL. Calculando o impacto econômico de mega-eventos esportivos. Disponível em: < http:// www.goldengoal.com.br/br/downloads/ Retorno_Jogos_Olimpicos.pdf $>$. Acesso em 23 set.2010.

LINHALES, M. A. Jogos da política, jogos do esporte: subsídios à reflexão sobre políticas públicas para o setor esportivo. In: MARCELINO, Nelson Carvalho. Lazer e esporte: políticas públicas. Campinas, SP: Autores Associados, 2001. p. 31-56.

MADRUGA, Djan. Megaeventos esportivos como gestão de custos oportunidade. In: DACOSTA, Lamartine et al. (Editores). Legados de megaeventos esportivos. Brasília: Ministério do Esporte, 2008. p. 59-64.

MASCARENHAS, Fernando. Megaeventos esportivos e Educação Física: alerta de tsunami. Movimento, Porto Alegre, v. 18, n. 01, p. 39-67, jan/mar de 2012. MAZO, Janice Zarpellon; ROLIM, Luis Henrique; DACOSTA, Lamartine Pereira. Em Busca de uma Definição de Legado na Perspectiva de Megaeventos Olímpicos. In: DACOSTA, Lamartine et al. (Editores). Legados de Megaeventos Esportivos. Brasília: Ministério do Esporte, 2008, p. 119-121.

MENICUCCI, Telma. Políticas de esporte e lazer: o estado da arte e um objeto em construção. In: ISAYAMA, Hélder; LINHALES, Meily (Orgs.). Avaliação de políticas e políticas de avaliação: questões para o esporte e o lazer. Belo Horizonte: UFMG, 2008. p.179-202.

MINAS GERAIS; BELO HORIZONTE. Programa Estado Para Resultados - ERP. 
Brasil (MG). Planejamento estratégico integrado: Projeto Copa 2014. Governo de Minas Gerais e Prefeitura de Belo Horizonte. Disponível em: < http:// www.estadopararesultados.mg.gov. $\mathrm{br} / \mathrm{dmdocuments/Planejamento}$ Estrat\%C3\%A9gico_Integrado_ Projeto_Copa_2014.pdf $>$. Acesso em: 28 Nov.2010.

RAEDER, Sávio. Jogos e cidades: ordenamento territorial urbano em grandes eventos esportivos. Brasília: Ministério do Esporte, 2010.

SOUZA, Marcelo. Mudar a cidade: uma introdução crítica ao planejamento e à gestão urbanos. 4 ed. Rio de Janeiro: Bertrand Brasil, 2006.
TAVARES, Otávio. Megaeventos Esportivos. Movimento, Porto Alegre, v. 17, n. 3, p. 11-35, jul/set de 2011.

VAINER; Carlos. A cidade do pensamento único: desmanchando consensos. Petrópolis: Vozes, 2000.

VILLANO, Bernardo; TERRA, Rodrigo. Definindo a temática de legados de megaevento esportivos. In: DACOSTA, Lamartine et al. (Editores). Legados de megaeventos esportivos. Brasília: Ministério do Esporte, 2008. p. 103-106. VILLANO, Bernardo et al. Seminário legados de Megaeventos esportivos: pontos de convergência. In: DACOSTA, Lamartine et al. (Editores). Legados de Megaeventos Esportivos. Brasília: Ministério do Esporte, 2008. p. 47-50.

THE WORLD CUP IN THE CITY OF BELO HORIZONTE: impacts and legacies

\section{ABSTRACT}

The announced impacts and legacies of the World Cup in the city of Belo Horizonte were investigated. Methodologically, this was a qualitative study, in which 6 managers were interviewed as a method of collecting data. It was concluded that there is a relationship of subordination between the event's logic and capital market's dynamics. This limitates any social gains which may be obtained. The managers only see the mega event as a 'business' and an opportunity of anticipating decisions and governmental support, to increase the flow of tourists and to promote the image of the city.

Keywords: World Cup; Football; Legacy

EL MUNDIAL DEL FÚTBOL EN LA CIUDAD DE BELO HORIZONTE: impactos y legados

\section{RESUMEN}

Se investigó los impactos y los legados del Mundial anunciados para la ciudad de Belo Horizonte. Metodológicamente, la investigación fue cualitativa y se entrevistó seis gerentes. Se concluyó que hay subordinación de la lógica del evento a la dinámica del mercado de capitales, lo que limita las ganancias sociales que se podrían obtener. 
Gerentes avistaron la realización del mundial como una oportunidad "de negocio" y anticiparse a las decisiones y los recursos del gobierno, para aumentar el flujo de turistas y promover la imagen de la ciudad. Los legados principales consistirían en los derechos económicos, infraestructura y capacitación.

Palabras clave: Mundial del Fútbol; Fútbol; Legado

Recebido em: fevereiro/2015 Aprovado em: abril/2015 